ESEJI

SEFEDIN ŠEHOVIĆ, redovni profesor

Univerzitet u Beogradu

Učiteljski fakultet, Novi Pazar

\title{
USLOVI RAZVOJA OSNOVNIH ŠKOLA U RAŠKOJ OBLASTI POČETKOM 20. VEKA
}

\begin{abstract}
APSTRAKT: U tekstu se razmatraju uslovi i mogućnosti za razvoj osnovnih škola na najnerazvijenijom području Srbije. Otežavajuća okolnost u tom razvoju bila je uslovljena narušenim odnosima dveju velikih sila Austro-Ugarske i osmanske Turske. Raška oblast (Novi Pazar, Sjenica i Tutin) predstavlja prostor gde su se odmeravale snage i branile granice pomenutih sila. To je uslovilo da je stanovništvo ovog područja bilo vrlo siromašno, obrazovanje na niskom nivou, mreža škola vrlo skromna, a interesovanje za školu slabo. To je doprinelo da se siromaštvo još više uveća, a uslovi života i rada u ovoj regiji postali su još teži.

Ključne reči: obrazovanje, škole, učenik, propisi, država
\end{abstract}

Građansko društvo sa svojim odlikama i institucijama u Raškoj oblasti imalo je izražene posebnosti. Upravo su ga te posebnosti učinile ne samo izrazito nerazvijenim, moguće i najzaostalijim između Triglava i Đevđelije, kako se to nekada govorilo, veoma nepovoljnim ambijentom za razvoj obrazovanja i kulture. Ove srpske zemlje iz srednjeg veka, pod osmanskom upravom 1459-1912, postale su tokom 19. veka izuzetno interesantne jer su se na njima prelamali neki odnosi i među velikih sila - AustroUgarske i Osmanske carevine. Tim pravcem su se odmeravale mogućnosti Zapada za „Drang nach Osten“ ali i izgledi Osmanskog carstva da brani zapadne granice carstva. Na taj prostor su mlade države Srbija i Crna Gora gledale kao na most međusobnog povezivanja, upravo onako kako je to bio most za razdvajanje tih država za protivnike njihovog zbližavanja i jedinstva. Velika neizvesnost je bila nadneta nad tamošnjim stanovništvom koje se kada je za to imalo iole povoljnih prilika iseljavalo za Tursku, kao što se pravoslavno stanovništvo iseljavalo za Srbiju i Crnu Goru, sklanjajući se od loših iskustava i teškog života na ovoj zemljouzini, kako su je nazivali pojedini geografi i istoričari. Tu se stanovništvo menjalo jer su na tom prostoru zastajali i naseljavali se stanovnici iz Bosne i delova Crne Gore, na svom migracionom putu prema istoku, odnosno Turskoj, među kojima veliki broj 
tzv. muhadžira. Raška oblast je postala pribežište i ne malog broja prebeglica iz ustaničke Srbije još od početka 19. veka i ispred akcija koje su u nekim delovima Crne Gore preduzimane protiv stanovništva „inovernog“. Ni jedno ni drugo stanovništvo - novi naseljenici u ovoj oblasti nisu se odlikovali ni tradicijom niti ljubavlju prema kulturi i obrazovanju. Kao i u prethodnom zavičaju i u ovom kraju naseljenik je nastavljao da živi bez svetovnih škola, gotovo bez zajedničke i organizovane inicijative u tom pravcu. Škole su otvarane sticajem okolnosti, najčešće verske i pri verskim ustanovama, bez uticaja stanovništva i njegovih potreba za savremenim životom.

Nezainteresovanost za obrazovanje proizlazila je iz organizacije života koja se lomila između feudalnih institucija i običaja, tradicije i kulture i buđenja savremenih potreba kod stanovništva koje je, ma kuda gledalo na istok ili zapad, sever ili jug - moglo videti drugačiji način života i više brige za svoju sadašnjicu i budućnost. U Novopazarskom sandžaku nije bilo ni minimalnih infrastrukturnih elemenata savremene organizacije gradova, centara, ustanova koje bi podržavale i činile neophodnim građanske institucije, među njima i škole.

Blizina Srbije je uticala i na obrazovanje u ovim krajevima. Ne to je prevashodno uticala pomoć koju su škole za srpsku decu dobijale od Srbije, ali i geografska blizina ovog područja i obeležjima žitelja na obe strane, srpskoj i turskoj. Ne samo u obrazovanju već se i u trgovini sarađivalo između Karanovca i Novog Pazara, na primer, po uspostavljanju granica posle prvog i drugog srpskog ustanka, a i kasnije.

Srbija je 1830. godine naziv svojih administrativno-upravnih jedinica - kneževina zamenila novim nazivom - serdarstva, a nahije su postale okružja koja će se stabilizovati kao okruzi. Užičko i čačansko okružje graničilo se sa Novopazarskim sandžakom i iz tih pravaca dolazili su razni oblici međusobnog povezivanja ovih područja, što se odražavalo i u radu i organizaciji škola. Slične pojave će se i kasnije reflektovati kada su serdarstva u Srbiji zamenjena okruzima (17 okruga) na osnovu Sretenjskog ustava, 1835. godine.

Uređivanje Srbije u oblasti obrazovanja, na primer Propisima kneza Mihaila 1863. godine, podsticalo je širenje škola i van njenih granica, tamo gde je živelo srpsko stanovništvo, ali ne na načelima koja su važila za Srbiju. Po tim propisima svaka opština koja je imala školu bila je školska opština, a takva opština morala je imati najmanje 25 đaka, tako da je svuda gde je bilo 400 domova otvorena osnovna škola. Kako obaveze za pohađanje škole nije bilo, a pismenost je donosila izvesne prednosti, škole su pripadale deci iz imućnih društvenih slojeva.

U Raškoj oblasti su tokom 19. veka kao varoši bili oformljeni Sjenica i Novi Pazar, oba mesta na putu, u izvesnom smislu transverzali između 
istoka i jugozapada, Stambola, Ušćupa (Skoplje), Novog Pazara, Taslidže (Pljevalja) i Sarajeva, i dalje Dubrovnika. U odnosu na uspon u srednjem veku, a kada su putopisci Novi Pazar opisivali kao veliku varoš „na Levantu“, sa stotinama i hiljadama dućana, mošeja, džamija, medresom, mektebima itd. „Na Senicah“ se pominje još u Srbiji 14. veka i kasnije kao pristaja uz dubrovački put i kao letnjikovac nekih srpskih vladalaca. Na prelomu 19. i 20. veka ove su varoši bile značajni administrativno-politički centri u ovom delu Osmanskog carstva - Novi Pazar kao sedište sandžakata, Sjenica kao sedište okruga. Tutin je naselje manjeg istorijskog značaja. Razvio se u gradić na istočnom delu Pešteri, sa desetak hiljada stanovnika, u kome se danas odvija značajan kulturni život.

To su tipične balkanske varoši koje su živele vekovima pod uticajima iz raznih pravaca i sa malim razvojnim aspiracijama stanovništva, koje je često harano nailaskom vojski i ratova iz raznih pravaca. Okruženju ovih varoši - sandžačkom selu, takve su varoši bile potrebne sa njihovim pijacama, panađurima, razmenom dobara između varoškog i seoskog stanovništva.

Nijedna od ovih varoši nije bila u prioritetima razvoja država u čijem su sastavu bile ili su prihvatale uticaj iz većih centara i naprednijih sredina. Isto tako nijedna se država nije odricala lako ovog područja, koje je u toj ravnoteži uticaja opstajalo u svojoj nerazvijenosti i zaostajanju. Na izvestan način zatvorene, te sredine su nastavljale život po obrascima koji su katkad poticali još iz srednjeg veka, nekada se čudno mešali sa savremenim urbanim središtima, a nekada iskakali sa velikim ambicijama u razvoju da bi one potom nanovo bile stišane i smirene u svojoj viševekovnoj zaostalosti. Imamo pre svega u vidu opstajanje i trajanje u ovim gradovima i naseljima više kulturnih slojeva koji su se odomaćivali i stotinama godina. Tu je upliv davnih vizantijskih i srpskih srednjovekovnih institucija i kulture, naročito preko spomenika kulture i stvaralaštva inspirisanog pravoslavljem i njihov uticaj na slikarstvo, muziku, građevinske objekte, alate i pribore i rad uopšte, naročito za poljoprivredu, folklor, običaje i obrede povezane sa životom naroda.

Veliki deo stanovništva prihvatio je islamske osnove i obrasce kulture i njima ispunjavao svoje životne tokove stotinama godina, naročito one povezane sa verskim životom, religijom, ali i sa običajima i obredima koji su postali tipični za kulturni život i stvaralaštvo muslimana. To stvaralaštvo, takođe, čine građevine, kulturni i verski spomenici, domovi za život građana, bogati običaji i folklor.

Naspram ta dva osnovna obrasca kulture drugi su imali manji uticaj poput grčko-cincarskog, srednjoevropskog, orijentalnog. Zaleđe gradova živi po svojim kulturnim obrascima, takođe pod najjačim uticajem pravoslavlja i islama kao religije i običaja u poljoprivredi, kulturi privređivanja i 
stočarenja na selu. To su žitelji sela na malim posedima, sa po kojim hektarom obradive zemlje, ali sa ispustima za stoku, na takozvanu jurtu, ničije zemljište, koje dobro dođe za puštanje i čuvanje stoke. Stočari su u najboljim vremenima za stočarenje držali na stotine ovaca po domaćinstvu, odnosno čitavih 100.000 ovaca pred Drugi svetski rat na Pešteri, a stanovništvo je živelo od stočnih proizvoda i sve potrebe zadovoljavalo iz tih izvora.

Tokom 1930. na delu Pešteri i njegovih obronaka stočari iz samo iz naselja ove tri opštine imali su impozantan broj „sitne stoke“ - ovaca 61.290, koza 16.139, pernate živine 31.570 i 4.511 košnica pčela. Na pašnjacima ove tri opštine bilo je i konja.

\begin{tabular}{|l|r|r|r|r|}
\hline \multicolumn{1}{|c|}{ Srez } & \multicolumn{1}{c|}{ Ovaca } & \multicolumn{1}{c|}{ Koza } & \multicolumn{1}{c|}{ Živine } & \multicolumn{1}{c|}{ Košnica } \\
\hline Deževski & 19.433 & 9.013 & 27.778 & 1.460 \\
\hline Sjenički & 31.939 & 4.252 & 8.275 & 1.987 \\
\hline Štavički & 19.918 & 2.874 & 5.517 & 1.074 \\
\hline
\end{tabular}

Jedan tip tradicionalnog, ali po svemu efikasnog stočarstva, prekinut je u vremenu socijalizma kada su prednost dobile velike stočne farme, naročito za gajenje ovaca i kada su nestali sa pešterskih pašnjaka bujuci sa stotinama ovaca $u$ privatnom posedu. Privatno stočno blago zamenjeno je zadružnim stočarenjem i farmama koje su zaposele stotine hektara jurta i pašnjaka i suzile mogućnosti za razvoj privatnog stočarstva. Priroda stočarenja uticala je da stočari čuvaju stečena iskustva, da paze na poruke preda$\mathrm{ka}$, da prepoznaju stanje stoke, naročito bolesti i dobro zdravlje, valjanu hranu, uslove smeštanja stoke u određene objekte leti i zimi. Razvili su kulturu stočarenja koja je obezbeđivala dobar uspeh. To su vekovima činili bez škole pa ni u 20. veku nisu osobito čeznuli za obrazovanjem. Obrazovanje ih je moglo odvojiti od poseda, a na to nisu lako pristajali, ili ih kultivisati što nisu smatrali potrebnim za svoj posao.

Svest da škola nije toliko neophodna za poslove sa stokom u ovim krajevima je bila oblik otpora obrazovanju. Škola, po tom načinu mišljenja, čak kvari decu, odvikavajući ih od prilježnosti seljačkim poslovima, odbija ih od njive, livade, štale, pa školovan mlad čovek postaje manje upotrebljiv i za seoske poslove. Ponekad je to bilo praćeno grubim protivljenjem školi iz usta seoskih mudrolija poznatom izrekom „ako hoćeš da imaš u kući budalu pošalji dete u školu“.

Poslovnost i uspešnost u primitivnom privređivanju postizani su i bez škole, kao što je i najveći deo trgovaca, zanatlija, posrednika u varošima sve svoje poslove obavljao bez pomoći škole. Ti su ljudi stasavali za poslove i životne uspehe i neuspehe bez obrazovanja, te se tradicionalno oformilo stanovište da škola i nije tako korisna i poželjna, da od nje ne zavisi život 
čoveka niti uspeh u radu. Sa tom zabludom borio se Sandžak i do polovine 20. veka, kada je osnovno školovanje postalo obavezno pod prinudom, zakonskom pretnjom, sankcijama, oštrim kaznama u slučaju izbegavanja takve obaveze. Vlast je te mere u ovim opštinama zaista i primenjivala.

Potreba da se i zakonskom prinudom svako dete privoli i privede pohađanju osnovne škole, iz osnova je promenila i do kraja aktuelizovala pitanje rada, organizacije i mreže osnovnih škola. Iz navedenih razloga, moguće, ovde više nego u drugim krajevima zemlje.

Postoje podaci koji govore da je Kraljevina Srba, Hrvata i Slovenaca pre 1929. godine imala teškoća i sa prehranom stanovišta mada je u svojim granicama obuhvatala lavovski deo Panonije, Pomoravlja, Mačve, Metohije itd. Siromaštvo i neprestana borba da se obezbedi prehrana i kakvo-takvo opstajanje porodica sa mnogo članova potiskivali su brigu za otvaranje i pohađanje osnovnih škola. Naprotiv, u školi se katkad prepoznavala smetnja za zapošljavanje dece i to od malih nogu, kao čobančića i za ispomoć u zemljoradnji i stočarstvu.

Pojedine analize životnih prilika i uslova u Kraljevini Jugoslaviji pokazivale su da stanovništvo gladuje u 120 srezova, a još više oseća „strah od gladi“ ili loše se hrani oko 50\% stanovništva. Glad za hlebom uvek je bila povezana sa glađu za zemljom, neprestanim bdenjem nad hlebom, uz davanje prednosti žitaricama među poljoprivrednim kulturama. U ovim krajevima se često ukupna situacija sa hranom svodila na dilemu - ima ili nema hleba, te osnove svake druge hrane.

U strukturi, hlebna žita su učestvovala sa $50-70 \%$, kukuruz u župskim, ravnim i ječam i raž u planinskim predelima ove oblasti. Pšenica nije mogla dostići ni 30\% u hlebu. Za jugoslovenske proseke „seosko stanovništvo je godišnje trošilo oko $322 \mathrm{~kg}$ hlebnog žita, dok je potrošnja varoškog stanovništva bila nešto manja". U ovoj oblasti ti su odnosi bili još nepovoljniji. Slaba ishrana je zbog dugotrajnog iscrpljivanja glađu izazivala teške zdravstvene posledice. Ljubodrag Dimić navodi podatke po kojima je između 1930-1937. u Jugoslaviji umrlo 267.173 bolesnika od tuberkuloze, ,jeftike", kako je nazivana u narodu. Tome je pogodovao način stanovanja i korišćenja prostora, najčešće u drvenim kućama, brvnarama. U istoj sobi su bili svi zajedno, stari i mladi, deca, zdravi i oboleli, muški i ženski. Ispred "odaje za spavanje“, „kuća“ sa ognjištem u sredini, iznad ovoga verige za vešanje kotlova i bakrača pri kuvanju, sadžak na ognjištu, okolo okačeni na kukama, drškama i zavrtnjima lonci, sita, rešeta, šerpe, alati, katkad kose i sekire. Visoko iznad lese i parošci, poprečno umetnute lenke na kojima se veša i suši meso na dimu, koji se izvija, najčešće iz slamnatih i drvenih krovova, šinde, bez dimnjaka, tokom cele godine, zimi i leti. Vrata su zatvarana drvenim mandalima i ključanicama. 
Prema Sretenu Vukosavljeviću, najpoznatijem učitelju iz Sandžaka između dva svetska rata i autoru Istorije seljačkog društva, seljak je imao lošije uslove života u kući nego tokom rada van kuće, na svom posedu. Rad van kuće je bio važniji, od toga su ukućani više zavisili nego od života i udobnosti u kući.

Nedostatak vode u kući, često i u blizini kuće, svodio je njenu potrošnju na najmanju meru. Katkad se nisu ni umivali dnevno, bilo je onih koji su to činili sedmično, pa i takvih koji su se umivali samo za praznične i svečane prilike. Leti se umivalo češće, zimi ređe. Slično je bilo i sa kupanjem. Potrošnja vode je bila nešto veća u islamskim porodicama, jer je njeno korišćenje bilo povezano sa pojedinim obredima. Spavalo se često u istom odelu u kojem se radilo.

Mnogi domaćinstvima viljuška nije bila potrebna, tanjir još manje, tako da su te delove pribora za jelo verovatno među poslednjim pribavile Sandžaklije, kako su još u srednjem veku nazivani ovdašnji stanovnici. Dominiralo je drveno posuđe i pribor koje su zimskih meseci seljani pravili sami: naročito štrublje, stapovi, bucati, kace i kačice, ćebad, kašike, mešalice (varjače) itd. Zarazne bolesti su lako prelazile sa jednog obolelog člana porodice na drugog, jer se jelo iz iste drvene ili keramičke posude, katkad i sa jednom kašikom za više članova. Upotreba metalne kašike i tanjira bila je važan doprinos higijeni, jer je smanjivala prenošenje oboljenja u krugu porodice.

Zemljani podovi u kući, ležajevi na podu, ognjišta kao izvor za kuvanje, zagrevanje i osvetljavanje prostorije, luč, sveća i petrolejka, kasnije peći od lima i šporeti na drva tek od 1930. godine, pribor za jelo, u kombinaciji sa ostalim uslovima života (vlaga, neuhranjenost, higijena, bezvodnost) pogodovali su pojavi i širenju tuberkuloze, tifusa i sličnih bolesti. U vezi sa tim praktikovano je nadrilekarstvo, širile se praznoverice, priče o šejtanima, kondžolosima, utvarama i svakakvim izazivačima zla i nevolja za ljude.

Osim drveta kuće su retko bile od kamena, ali često i od čatme, ćerpiča (nepečena cigla), bondruka dok je, istina retko, postojao i čardak, najčešće namenjen gostima i za posebne potrebe. Stočari u selima nisu naročito držali do kuće koliko do ambijenta u koji su sa seoskih poslova dolazili na konak i boravak. Uz kuće su bile kolibe, ponekad koliba za svakog odraslog člana porodice, najčešće jedna prostorija, bez patosa, samo sa poravnatom zemljom i sa stvarima članova porodice koji su je koristili. To su bili hambari i koševi za žito, štale, torovi itd. Neke od tih koliba često su služile za smeštaj tek otvorenih škola. Veća koliba je imala prostirke ispod dasaka na kojim su sedeli učenici ili tronošce, trupine, šamlice koje su učenici donosili od kuća. To je bio začetak škola u zabačenim selima ove oblasti i način na koji su deca počela svoje obrazovanje. 
Kultura rada, bavljenja poljoprivredom na selu, stočarenje, zemljoradnja, u ravničarskim krajevima voćarstvo i drugo zasnivano je na primitivnoj tehnologiji i na „motičkoj zemljoradnji“, sa pravom konstatuje Lj. Dimić. Dominiralo je ručno obrađivanje zemlje, ali su sa kapitalizacijom društva i tokom 20. veka vo i konj kao ručna snaga ostali glavni oslonac poljoprivrednicima sa primitivnim sredstvima za obradu zemlje. To su najčešće bili drveno ralo, kosa koju priprema sam kosač, saone, drvena kola, retko metalni plugovi sa jednim raonikom i pribori, alati i oruđa najčešće domaće izrade (rala, drljače, vile, grabulje, kudelje). Interesantna su drvena kola, napravljena bez metalnih delova, čak i bez eksera, pogodna za sporu vožnju, koja je vukao par ili ponekad dva para volova. Kola su imala veliki i mali pod, Na „velikom podu“ isključivo se prenosila kabasta sadržina, seno, slama, snoplje. Natovare se na udaljenim delovima poseda. Gazda upregne volove da vuku, popne se na natovareno seno, leži, nekada i spava dok volovi vuku i stižu do kuće vez vodiča. Tim povodom šalili su se Pešterci izrekom „Užih puteva i širih kola, luđih ljudi i pametnijih volova nigde na svetu nema kao na Pešteri." Taj kraj bez škola, ali sa bogatim pašnjacima i velikom stadima, buljucima, krdima stoke šaljivo su nazivali „stočarski svet“ i u islamskom žargonu „hajvan vilajet“.

Navedenih pojava bilo je manje u gradovima, ali intenzivno kod pripadnika različitih vera i naroda. Nasuprot tome stajali su nerazvijena prosveta i veoma nizak nivo obrazovanja, jer su mnoga sela ušla duboko u 20. vek bez škole i bez mogućnosti da školuju brojnu decu. U varošima je takođe bilo nedovoljno škola, bez odgovarajućih zgrada.

U Raškoj oblasti osnovna škola je otvarala vidike njenih žitelja, pomagala da se odneguju i obrazuju nova pokoljenja omladine koja će se smeštati u taj ambijent drugačije od svojih predaka. To će trajati sve očiglednije odmicanjem i isticanjem 20. veka, kada će se i u najudaljenijim predelima i naseljima ove oblasti sve više prepoznavati nove kulturne i civilizacijske vrednosti savremenog života.

Već 25. juna 1919, ministar Davidović je podneo Narodnoj skupštini Predlog zakona o narodni školama, koji je imao u vidu potrebu da se osnovno obrazovanje unificira, da se pripreme jedinstveni programi i usaglasi zakonodavstvo u ovim školama nastalo pre ujedinjenja u raznim krajevima zemlje i pod raznim uticajima. Komisiju za tako delikatan posao činili su ugledni profesori uglavnom iz Beograda i više školskih nadzornika i učitelja pretežno iz gradova koji su bili kasnije sedišta banovina. U toj komisiji nije bilo ljudi koji bi zastupali stanovišta i interese vrlo nerazvijenih područja zemlje. Iz tih razloga promene nisu donosile posebne novosti za ovu oblast, osim što su jedinstveni programi za osnovnu nastavu protegnuti i na ovo područje, ali u krajnje neravnopravnim uslovima, jer je upravo u toj oblasti 
bilo malo škola, veliki natalitet, raznoliko stanovništvo s obzirom na tradiciju, pripadnost veri, narodnost i drugo.

U tom smislu se i ne može govoriti o primeni određene prosvetne politike u obrazovanju na ovom području, već se pre radilo o najnužnijim poslovima i izvođenju nastave u uslovima siromaštva i oskudice, odnosno nastojanju da se podignu nove školske zgrade namenjene osnovnoj nastavi. To su posle Drugog svetskog rata bili prvi objekti namenski rađeni za osnovne škole u ovim krajevima, pre svega u seoskim centrima i planinskim predelima. Glavni zadatak je bio otvaranje i podizanje škola, koje su na svojim počecima bile daleko od značajnijeg uticaja na svoju sredinu, kulturu, pismenost i obrazovanost stanovništva.

Godine 1928. komisija za izradu državnog prosvetnog programa donela je više rezolucija, između ostalog i o osnovnim školama u kojoj je ocenjeno kako je brojni raspored osnovnih škola po zemlji disharmoničan i da se hitno mora pristupiti sistematskom otvaranju osnovnih škola. U rezoluciji se govorilo o potrebi da se osnovno obrazovanje uredi saglasno nacionalnim i osnovnim uslovima školovanja, da se osnovna škola formira u dva nivoa, $4+4$ razreda (niži i viši razredi), da se u ovoj školi više brine o siromašnoj i defektnoj deci, o obdarenim učenicima itd. Sa gledišta naše teme, najvažniji su akcenti u prvom delu ove rezolucije.

Za osnovne škole u ovoj oblasti, poseban značaj je imala i Rezolucija o materijalnom stanju naših škola u kojoj Komisija upozorava da je materijalno snabdevanje tako oskudno da škola ne može izvoditi ni svoje osnovne zadatke. Ovakva ocena je podudarna sa srednjom ocenom mreže škola od iste komisije, te se i po tome može ceniti kako su kompetentne institucije onovremene Jugoslavije ocenjivale mrežu osnovnih škola i posledice njene nesavršenosti i nedovoljnosti. Siromašna škola siromašnih, nerazvijenih krajeva zemlje nije raspolagala zgradama, sredstvima za nastavu, za higijenu, za zagrevanje i održavanje objekata, nameštajem, zbog čega je predstavljala najveću slabost onovremenih osnovnih škola u čitavoj zemlji. Istom rezolucijom bilo je predviđeno da produžne škole, sa šest ili osam razreda, obavezno imaju školski vrt, do dva hektara, „objekte“ za „očiglednu nastavu" (tople leje, rasadnik za voće, baštu, sortimente voćnjaka i loze, lucerište, pčelinjak, živinarnik i drugo) što je bilo veoma daleko od mogućnosti u školama nerazvijenog područja, među kojima gotovo da nije bilo onih $4+2$ razreda.

Transformacije obrazovnih ideja u pedagošku praksu u tom vremenu su bile dugotrajne i katkad veoma bolne, ostvarivane uz izuzetne napore. Prednji slučaj to nesumnjivo pokazuje kada je između odredbe „treba" i „dužno je" da pohodi školu bilo potrebno gotovo pune dve decenije nastojanja i truda jedne male države kakva je bila Srbija. 
Propisima je ozakonjeno da se mora uspostaviti mreža škola i da svako dete može doći do škole i vratiti se tokom dva dana svojoj kući. To je bio razlog da se najveća pažnja posveti školskim zgradama koje čine primarno obeležje mreže osnovnih škola. Zato su još 1881. u Srbiji doneta pravila o podizanju školskih zgrada, što je takođe bio doprinos poboljšanju rada, organizacije i mreže osnovnih škola. Upravo takva okolnost je bitno određivala neke aspekte rada osnovnih škola tokom čitavog 20. veka, posebno u Kraljevini Jugoslaviji.

Kako je „dužnost“ da sva deca pohađaju osnovnu školu važila za sve građane zemlje, mreža osnovnih škola je morala da obezbedi izvršenje te obaveze. Dostupnost svake osnovne škole detetu postalo je najvažnije obeležje mreže osnovnih škola, ali i prvi uslov osnovnog školovanja. Zato su prestali da važe propisi iz 19. veka, jer oni takve obaveze nikada nisu ispunili i taj segment Zakona o narodnoj (osnovnoj) školi, bez obzira kada je donet u 19. veku, nije ostvaren u Kneževini Srbiji posle toga, ni u Kraljevini Jugoslaviji u prvoj polovini 20. veka.

U poređenju sa evropski orijentisanom Srbijom, što je bilo od uticaja na srpsko stanovništvo, pa i na popularisanje i zasnivanje osnovnog obrazovanja ne samo u zemlji već i u predelima Raške oblasti, bilo je očigledno da ni u Osmanskoj carevini ni na području Novopazarskog sandžaka do 1912. osnovne škole nisu bile dostupne svoj deci. O tome svedoči stanje obrazovanja na području Raške oblasti tokom čitavog 20. veka. Kratko vreme između Mladoturske revolucije (Hurijeta) 1908. i Balkanskih ratova nije donelo znatne promene, kao što ni kasnije, iz poznatih razloga, ni uticaj Turske Kemala Ataturka i njegovih reformi u smislu evropeizacije Turske nisu imali primetan uticaj u ovoj oblasti, osim što se u izvesnoj meri kod muslimanskog stanovništva menjala svest o značaju obrazovanja.

Dok su u Kneževini Srbiji uređivani odnosi u obrazovanju, planirana i kontrolisana „rasprostranjenost“ osnovnih škola, u Sandžaku - udaljenom od centra osmanske vlasti, u nesigurnim i odveć isturenim delovima carevine - gotovo da nije bilo tvrdih normi niti propisa kojima je uređivan ovaj domen života zajednica pod osmanskom upravom. Škole za pripadnike islamske veroispovesti za decu i omladinu zavisile su od verskih, islamskih (šerijatskih) propisa. Po njima, škole su mogle biti otvarane tamo gde je bilo ljudi koji bi na tome radili, pa su uglavnom varoši, odnosno kasabe, imale najviše raznih škola. Tu su bile verske škole počev od mekteba do medrese, kojih je bilo više $u$ istoj sredini. Najčešće su to bile škole $u$ okviru džamija, po kojima su, po pravilu, nosile ime. Ređe su imenovane po mualimi, odnosno mualimu. Meketbi su često nosili imena po hanumama koje su u njima bile učiteljice ili po učiteljima. 
Sefedin Šehović

\section{NASLOV \\ Summary}

The education system of Serbia in the 20 century, in some parts of its burdens and violates underdevelopment. This system has evolved with its many specific areas of basic education, with Pester, Pester plateau and Sjenički field and with the upper sides of Raška and Vapa, where for centuries evolved mountain village with a parish and towns of Novi Pazar, Raška, Sjenica on the Vapa river and Tutin on Vidrewak. With a special climate of that part of the old Raška and sawak of Novi Pazar, a former course of history, have acquired a variety of circumstances development of this area. Named for a variety of historians and researchers Stara Raška, Novi Pazar, Raška, Rasa valley, The territory of Ras and Raška region, which was accepted and in this paper, considering the former territory of the three alliances, now three municipalities: Novi Pazar, Tutin and Sjenica. This area has played a significant role in history as a link and the attention of neighboring imperial powers of the 19th century, Ottoman Turkey and the Habsburg monarchy, but as the isthmus (Cvijić) and a corridor to separate two independent Serbian-state of Berlin Congress, 1878. Sjenica and Tutin, were annexed to Serbia, among other changes, which brings liberation this region, after the current issue of basic education and primary schools in this part of Serbia, Raska region. In order for a primary school education strongest segment of the system associated with the achievement of general culture, population, literacy and the concurrence of knowledge which enables a higher level of communication between people and regions of the country introducing people to the European standards of life and civil society. Ottoman Turkish was in that part of their empire, but the western city of Turkey to the center of interest for the school in these areas was observed, since the second half of the 19th century was the first secular schools, and given, for the education of children of various ages, subjects Turkey in this region. Kingdom of Serbia establishes national primary school for their children, regardless of religion, ethnicity and other differences, until the end of the 20th century to the present, developed within the educational system of Serbia, are an integral part. 


\section{Literatura}

Aličić, S., Turski katastarski popisi nekih područja zapadne Srbije XV i XVI veka, Čačak 1984.

Andrejević, A., Spomenici islamske umetnosti, Novi Pazar i okolina, Beograd 1969.

Bajić, Lj., Školstvo u trsteničkom kraju od 1913-1983, Trstenik 1985.

Cvijić, J., Država Srba, Hrvata i Slovenaca, Beograd 1920.

Dimić, Lj., Jugoslovenska država, društvo i prosvetna politika, Ministarstvo prosvete i ministri od 1918. do 1941, Beograd 2000.

Grujić, V., Osnovnoškolsko vaspitanje i obrazovanje u Srbiji do sticanja nezavisnosti, Beograd 1994.

Kačapor, S., Školstvo u Novom Pazaru i okolini od 1918. do 1941. godine, Novi Pazar 1987.

Nedović, V., Novi Pazar i okolina, Beograd 1969.

Vranc, E., Dolgan, J., Nastavni program za narodne škole u Kraljevini Jugoslaviji, Beograd 1938.

\section{Dokumentacija}

Almanah - šematizam Zetske banovine, Sarajevo 1931.

Adresar osnovnih škola na teritoriji sreza Kraljevo, Kraljevo 1964.

Ćatović Begović, Z., Vaspitanje ženske dece u Novom Pazaru i uticaj sredine na njihovo prevaspitavanje, rad za stručni učiteljski ispit, Novi Pazar 1955.

Mujagić, S., Uloga učitelja u vanškolskom radu u srezu sjeničkom, rad za stručni učiteljski ispit, Novi Pazar 1954. 